\title{
A estatística articulada com o tema transversal meio ambiente: uma experiência com alunos dos anos finais do ensino fundamental
}

\section{Statistics integrated to the transversal theme natural environment: one experience with students of the final years of elementary school}

\author{
Karine Machado Fraga de Melo ${ }^{1}$ \\ karinemfm@ig.com.br
}

\author{
Claudia Lisete Oliveira Groenwald ${ }^{2}$ \\ claudiag@ulbra.br
}

\begin{abstract}
Resumo
Este artigo apresenta a implementação (desenvolvimento, aplicação e avaliação) de uma sequência didática eletrônica com conceitos estatísticos, para o $9^{\circ}$ ano do Ensino Fundamental, articulados com o tema transversal Meio Ambiente. Neste trabalho apresentamos o ambiente de investigação desenvolvido na plataforma SIENA (Sistema Integrado de Ensino e Aprendizagem). O SIENA é uma plataforma de ensino que foi desenvolvida em parceria entre o Grupo de Estudos Curriculares de Educação Matemática (GECEM), da Universidade Luterana do Brasil e o Grupo de Tecnologias Educativas, da Universidade de La laguna (ULL), em Tenerife, Espanha. Os resultados apontam que a aplicação da sequência didática eletrônica contextualizada com questões ambientais contribui para o processo de ensino e aprendizagem de conceitos estatísticos desenvolvidos no $9^{\circ}$ ano do Ensino Fundamental, visto que: proporcionou aos alunos a revisão e o aprofundamento dos conceitos estatísticos que já haviam sido estudados em sala de aula e também, o acréscimo de novos conceitos; favoreceu um ambiente de cooperação e construção do conhecimento entre os alunos, onde o professor desempenhou o papel de facilitador e mediador do processo de ensino e aprendizagem.
\end{abstract}

Palavras-chave: Ensino de Estatística. Sequência Didática Eletrônica. Tema Transversal. Meio Ambiente. Sistema Integrado de Ensino Aprendizagem SIENA.

\begin{abstract}
This article presents the implementation (development, application and evaluation) of an electronic didactic sequence for Statistics concepts, for the 9th year of Elementary School, integrated to a transversal theme, "Natural Environment". This paper presents the developed a research environment in the Teaching and Learning Integrated System (SIENA). The SIENA is a learning platform developed in partnership between Grupo de Estudos Curriculares de Educação Matemática (GECEM), Lutheran University of Brazil (ULBRA) and Grupo de Tecnologías Educativas, Universidad de La Laguna (ULL), Tenerife, Spain. The results indicate that the electronic didactic sequence on Natural Environment helps the teaching and learning process of Statistics concepts taught in the 9th year of Elementary School. The sequence (1) allowed pupils to revise and deepen Statistics contents previously learned in the classroom and to learn new concepts, and (2) promoted a

\footnotetext{
1 Mestra em Ensino de Ciências e Matemática pelo Programa de Pós-Graduação em Ensino de Ciências e Matemática da Universidade Luterana do Brasil.

2 Doutora em Ciências da Educação pela Pontifícia de Salamanca na Espanha, professora do Curso de Matemática e do Programa de Pós-Graduação em Ensino de Ciências da Universidade Luterana do Brasil.
} 
cooperation environment for the construction of knowledge for pupils in which the teacher performed the role of facilitator and mediator of the teaching and learning process.

Keywords: Teaching Statistics. Electronic Didactic Sequence. Transversal Theme. Natural Environment. Teaching and Learning Integrated System SIENA.

\section{Introdução}

Este artigo apresenta uma sequência didática eletrônica com os conceitos estatísticos articulados com o tema transversal Meio Ambiente, direcionada para alunos do $9^{\circ}$ ano do Ensino Fundamental.

A forma como a Educação Ambiental foi incluída nos Parâmetros Curriculares Nacionais (PCN) (BRASIL, 1998) reconhece que a escola assume um papel fundamental na formação de cidadãos ativos e responsáveis resgatando valores essenciais como a ética, a fraternidade e respeito da vida em geral. Devido a abordagem holística e integradora da Educação Ambiental ela é trabalhada nos PCN (BRASIL, 1998), através da proposição do Meio Ambiente como tema Transversal.

A escolha do Meio Ambiente como um dos seis temas transversais foi definido de acordo com quatro critérios básicos: urgência social, questões de abrangência social, possibilidade de ensino (aprendizagem no Ensino Fundamental), favorecimento da compreensão da realidade e da participação social (tomada de posicionamento frente às questões que interferem na vida coletiva) (BRASIL, 1998).

A Educação Matemática deve considerar que a compreensão e a tomada de decisões diante de questões políticas e sociais dependem da leitura crítica e interpretação de informações complexas, que incluem dados e índices divulgados pelos meios de comunicação. A escola deverá, então, preparar os alunos para as necessidades e problemas do mundo em que estão inseridos. Para tal, alfabetizar estatisticamente os alunos, de modo a perceberem as informações que lhes chegam, é desenvolver-lhes a capacidade de argumentar e intervir sobre elas (RIBEIRO, 2005).

Neste trabalho, apresenta-se o ambiente de investigação, implementado no Sistema Integrado de Ensino e Aprendizagem (SIENA), com o conteúdo de Estatística direcionado aos estudantes do $9^{\circ}$ ano do Ensino Fundamental. É uma plataforma de ensino desenvolvida para estudos de um tema qualquer. O SIENA é resultado da parceria entre o Grupo de Estudos 
Curriculares de Educação Matemática (GECEM), da Universidade Luterana do Brasil (ULBRA) e o Grupo de Tecnologias Educativas, da Universidade de La Laguna (ULL) de Tenerife, Espanha. É um sistema inteligente que possui duas opções de uso: a primeira serve para os alunos estudarem determinado conteúdo, realizando os testes adaptativos ${ }^{3}$ para avaliarem os conhecimentos adquiridos e, a segunda opção, oportuniza aos estudantes a realização do teste adaptativo e a recuperação individualizada das dificuldades que o estudante apresentou.

Nesta investigação o SIENA foi utilizado para estudo de um tema através da implementação (desenvolvimento, aplicação e avaliação) de uma sequência didática eletrônica articulando conceitos estatísticos com o tema transversal Meio Ambiental direcionada para estudantes dos anos finais do Ensino Fundamental.

Parece-nos essencial à formação dos alunos o desenvolvimento de atividades estatísticas contextualizadas, que envolvam desde uma estratégia de resolução de problemas até uma análise dos resultados obtidos, a fim de garantir a possibilidade do desenvolvimento do pensamento estatístico que contribua para a formação de cidadãos críticos e participativos.

\section{A matemática e o tema transversal meio ambiente}

Segundo Groenwald e Silva (2001), a construção de um currículo matemático, considerando os temas de relevância social, confere ao mesmo uma perspectiva integradora e, nesse sentido, sua organização se estabelece em torno de situações e problemas de interesse que permitam a leitura, compreensão e interação da realidade social, cultural, política e natural. Um tema de relevância social é, sem dúvida, a Educação Ambiental.

De acordo com Perez e Paulo (2008), uma das medidas urgentes é reavaliar o processo educacional vigente. Torna-se necessário repensar as ações pedagógicas e caminhar para uma educação que vise à formação de alunos capazes de refletir sobre as questões ambientais.

Dessa forma, a preservação do Meio Ambiente passa, indiscutivelmente, pela mudança de mentalidade, e essa pode ser alcançada através da educação, trabalhando esses conceitos na

\footnotetext{
${ }^{3}$ Um teste adaptativo informatizado é administrado pelo computador, que procura ajustar as questões do teste ao nível de habilidade de cada examinando. $\mathrm{O}$ teste adaptativo tem por finalidade administrar questões de um banco de questões previamente calibradas, que correspondam ao nível de capacidade do examinando.
} 
escola, a qual é um polo divulgador e um dos responsáveis pelas mudanças de atitudes (GROENWALD; SILVA, 2001).

O ensino de Matemática pode auxiliar o aluno na compreensão do cotidiano e na sua intervenção no Meio Ambiente, portanto, colaborar na formação de um cidadão crítico (POSSAS, 2003, p. 3). Através da Matemática é possível entender e discutir questões econômicas, sociais e ambientais, perceber e questionar as injustiças, comparar as diferenças salariais, entender índices e gráficos, entre outros.

A Matemática não pode ser reconhecida como uma disciplina pronta e acabada, mas como uma disciplina que está em constante evolução, tem uma história e esta precisa ser aproveitada também na sala de aula (MUNHOZ; DINIZ, 2006). Está relacionada com os acontecimentos diários, sendo assim viva e dinâmica, de acordo com D’ Ambrósio (2001, p. 15), "o grande desafio que nós educadores matemáticos, encontramos é tornar a Matemática interessante, isto é, atrativa, relevante, isto é, útil, e atual, isto é, integrada no mundo de hoje". Falta na maioria das escolas uma Matemática voltada para a descoberta, exploração e resolução de problemas reais, que não tenham respostas prontas, mas possam ser discutidas diferentes soluções possíveis. Ou seja, uma Matemática que instigue nos alunos o espírito da curiosidade, exploração e satisfação ao encontrarem uma solução mais adequada ou até mesmo por não encontrarem solução.

De acordo com os PCN, (BRASIL, 1998) o conhecimento matemático, deve contribuir para a capacidade crítica reflexiva na formação do educando, levando-o a entender o verdadeiro papel da Matemática em nossa sociedade. "[...] A Matemática é muito mais do que a Ciência dos números, das abstrações ou do espaço, ela é constituída de um amplo espectro de Matemáticas que se intercomunicam numa lógica de relações fundamental para as aprendizagens do ser humano" (GIGANTE; SANTOS, SILVA, 2009, p. 37).

O ser humano faz parte do Meio Ambiente e estabelece relações de acordo com o espaço que está ao seu redor e com todos os outros elementos ou seres vivos que com ele interagem. Portanto, esse tema pode apresentar de acordo com o conteúdo matemático, a forma procedimental da coleta, organização e interpretação de dados estatísticos e outras situações que possam auxiliar na tomada de decisões sobre a prevenção do Meio Ambiente (como, a preservação da camada de ozônio, desmatamento, poluição). 
Assim, consideramos que o estudo de conceitos estatísticos contextualizados a questões de importância social tornam-se relevantes para os anos finais do Ensino Fundamental, pois possibilitam aos alunos o desenvolvimento da capacidade de coletar, organizar, interpretar e comparar dados para obter e fundamentar conclusões, que segundo Lopes (2008), é a grande base para o desenvolvimento de uma atitude científica.

\section{Aprendizagem e atividades didáticas com conceitos estatísticos}

A formação básica em Estatística e Probabilidade torna-se indispensável ao cidadão nos dias atuais e em tempos futuros. Numa sociedade baseada cada vez mais na comunicação e na tecnologia, coligir, organizar, descrever, exibir, interpretar dados e tomar decisões ou fazer previsões com base nessa informação são capacidades importantes a desenvolver (BROCARDO; MENDES, 2001). Por outro lado, de acordo com Almeida (2002), tratando-se de um domínio para descrever o real, a Estatística não pode ser ensinada de modo convencional, uma vez que não prepara os alunos para o mundo que os rodeia. A este respeito, Carvalho (2004, apud Carvalho et al 2007) refere que o tipo de tarefas e o modo como os alunos se envolvem na sua resolução é determinante para a qualidade dos seus desempenhos.

O estudo das concepções e propostas para o ensino de Estatística nos anos finais do Ensino Fundamental está proposto para ser desenvolvido em torno da resolução de problemas, a partir de situações da vida real do aluno, de modo a promover o significado, a motivação e o interesse dos estudantes, em contraste com o ensino centrado no professor e em atividades rotineiras, em que a principal preocupação é a aplicação de fórmulas e procedimentos, ficando a interpretação para segundo plano (BATANERO, 2000; CARVALHO, 2001; CARVALHO; CÉSAR, 2001).

No sentido de o aluno construir o seu próprio conhecimento, o professor deverá criar situações didáticas que permitam a discussão e a reflexão sobre os problemas (MACHADO, 2000 apud CARVALHO et al, 2007) e que desenvolvam aptidões para construir, ler e interpretar diferentes formas de apresentar os dados; para recolher e organizar dados de problemas simples, relacionados com as suas vivências e interesses; e para analisar e interpretar os dados estatísticos. 
Simultaneamente, é preciso contribuir para o enriquecimento das práticas pedagógicas, fomentando e valorizando os trabalhos de grupo, a realização de projetos, as atividades exploratórias e de investigação e o gosto pela resolução de problemas, incrementando as discussões e as reflexões críticas, bem como, a aplicação de instrumentos e metodologias inovadoras para uma participação ativa dos alunos (MACHADO, 2000 apud CARVALHO et al, 2007).

Segundo Almeida (2002), aprender Estatística significa desenvolver a capacidade de "fazer" Estatística, a qual não se reduz apenas ao domínio das técnicas quantitativas, mas sim às competências para explorar, conjecturar, raciocinar, argumentar e comunicar em termos quantitativos, e também, para recorrer a uma gama variada de métodos e de ferramentas estatísticas, tendo em vista resolver problemas não rotineiros, sintetizar ideias, estabelecer relações e inferências.

Conforme os PCN (BRASIL, 1998), as pesquisas sobre saúde, meio ambiente, trabalho e consumo, poderão fornecer contextos em que os conceitos e procedimentos estatísticos ganham significado. Nesse sentido, os vários conteúdos matemáticos/estatísticos podem ser considerados como "ferramentas" que auxiliem o aluno a enfrentar e lidar com as mais diferentes situações-problema e, desse modo, a descobrir e adquirir novos conhecimentos.

O objetivo de ensinar Estatística deve sempre estar acompanhado do objetivo de desenvolver a criticidade e o engajamento dos estudantes nas questões políticas e sociais relevantes para sua comunidade (CAMPOS et al, 2011).

Nesta investigação, os conceitos estatísticos são contextualizados a questões ambientais, pois acredita-se que a ênfase apenas na parte da Estatística Descritiva, seus cálculos e fórmulas não levarão ao desenvolvimento de um ensino que possibilite aos estudantes à reflexão de temas de relevância social .

\section{Metodologia da investigação}

Para investigar como a implementação de uma sequência didática eletrônica contextualizada com questões ambientais contribui para o processo de ensino e aprendizagem de conceitos estatísticos a serem desenvolvidos nos anos finais do Ensino Fundamental, foi necessário a construção do ambiente de investigação, no sistema inteligente de ensino SIENA, desenvolvido com as seguintes ações: 
- construção do grafo com nodos ${ }^{4}$ sobre os conceitos básicos de Estatística;

- elaboração da sequência didática eletrônica, com os conceitos básicos de Estatística para os anos finais do Ensino Fundamental, inseridas no SIENA, para cada nodo do grafo;

- construção do banco de questões, que foram cadastradas no SIENA. As questões foram elaboradas e adaptadas, tendo como base a análise das atividades didáticas e exercícios presentes em livros didáticos para o nono ano. Para cada nodo do grafo foram desenvolvidas 30 questões, classificadas em fáceis, médias e difíceis, com cinco opções de resposta cada uma, para a realização dos testes adaptativos em cada nodo do grafo. As questões elaboradas tiveram por finalidade a identificação das dificuldades dos alunos nos conceitos de Estatística estudados e a autoavaliação.

Foi realizada uma experiência, utilizando o ambiente construído no SIENA, com uma amostra de 33 alunos que estavam cursando o $9^{\circ}$ ano do Ensino Fundamental, em uma escola Estadual do munícipio de Porto Alegre.

\section{Construindo o design do ambiente de investigação no siena}

Para a implementação da experiência no SIENA construiu-se inicialmente um mapa conceitual com os conceitos estatísticos que seriam abordados no material de estudo da sequência didática eletrônica, nas questões e atividades didáticas. $\mathrm{O}$ mapa conceitual foi construído seguindo as orientações dos PCN (BRASIL, 1998) para o bloco de conteúdos Tratamento da Informação.

A seguir, desenvolveu-se o grafo dos conteúdos a serem trabalhados no SIENA, fundamentados nos conceitos estatísticos apresentados no mapa conceitual, Figura 1.

\footnotetext{
${ }^{4}$ São os conceitos que fazem parte do grafo.
} 
Figura 1 - Mapa conceitual com os conceitos estatísticos.

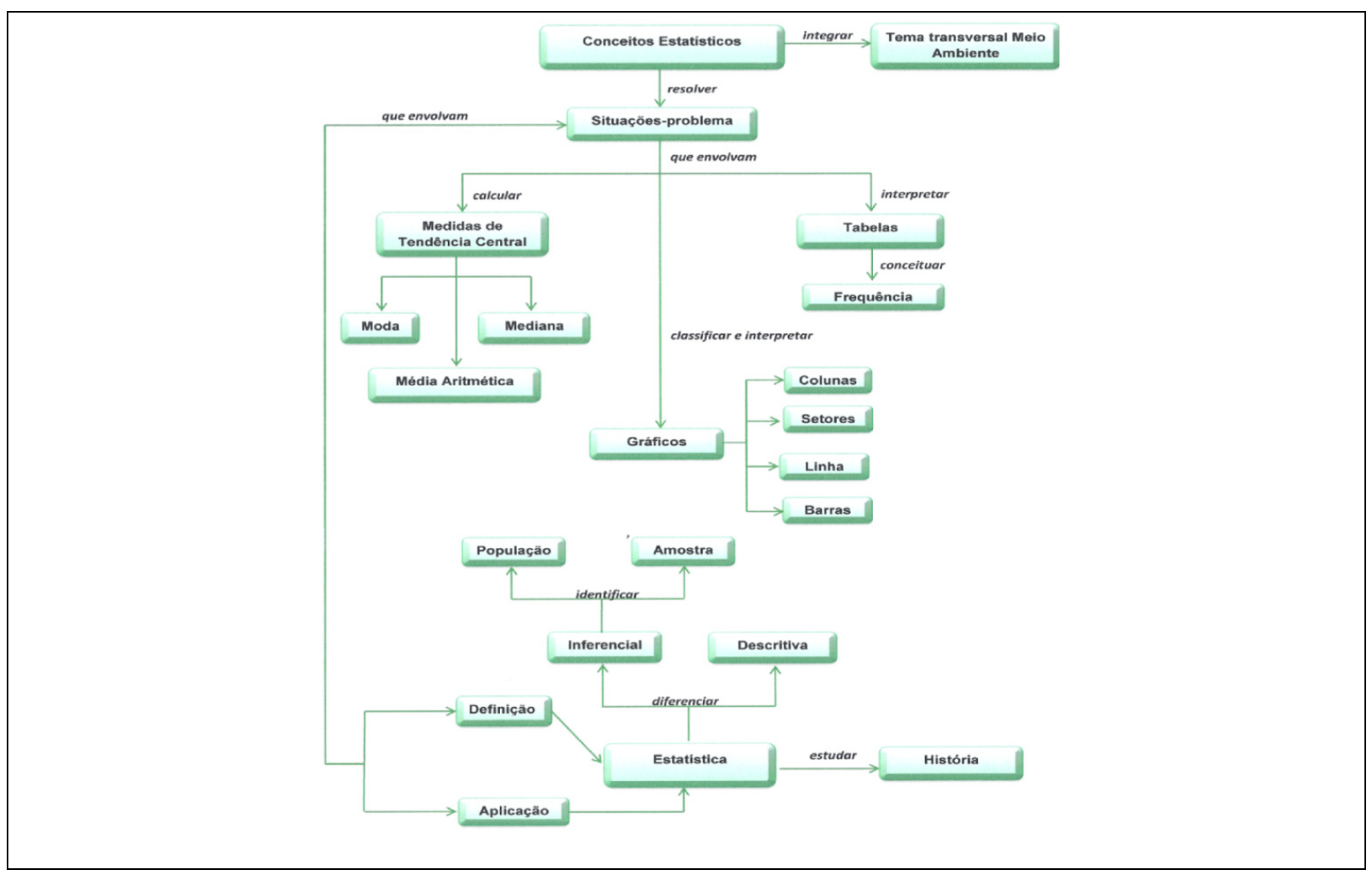

Fonte: a Pesquisa

O grafo foi construído no software Compendium e importado para o SIENA possuindo seis nodos: Introdução à Estatística; Tabelas; Gráficos; Medidas de Tendência Central; Estatística e Educação Ambiental Resolução de Problemas e Conceitos Básicos de Estatística, conforme representados na Figura 2.

Figura 2 - Grafo dos nodos com os conceitos estatísticos.

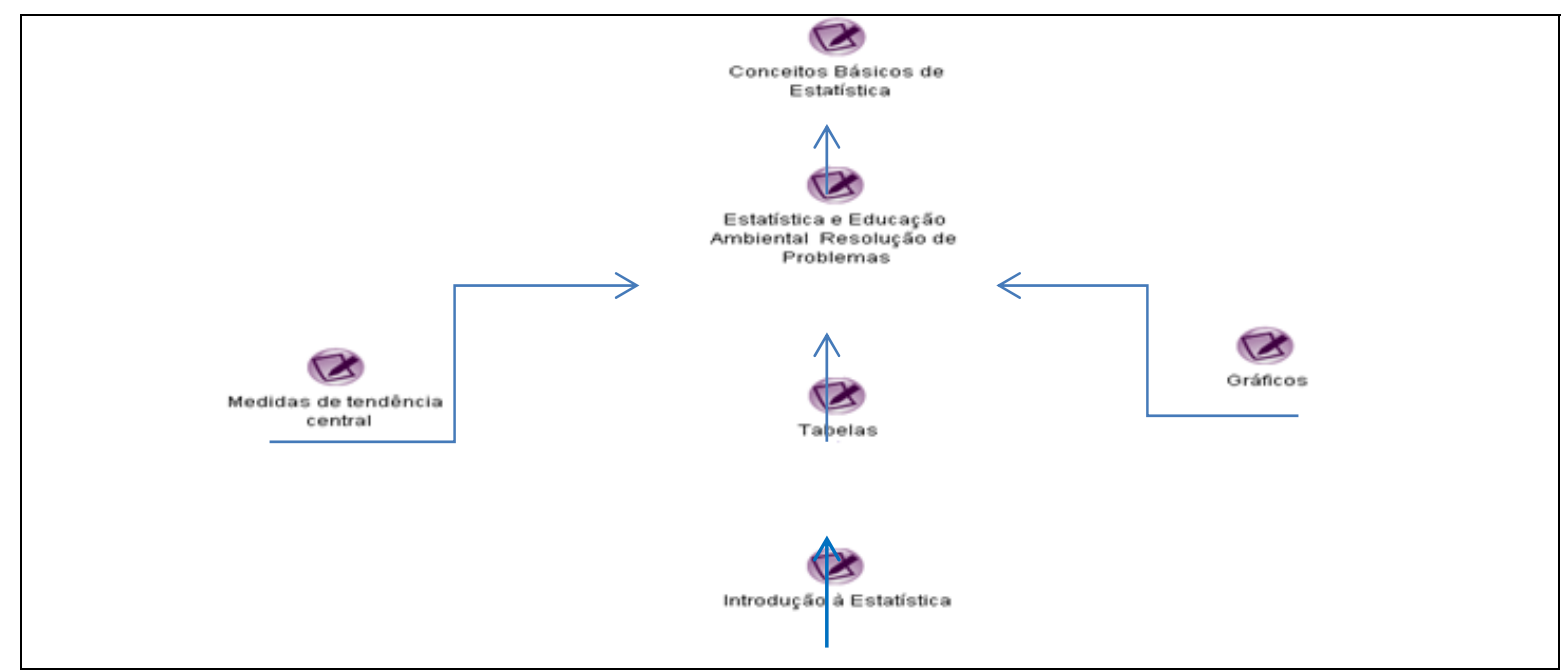

Fonte: http://siena.ulbra.br 
Nesta investigação o sistema SIENA foi utilizado para os alunos estudarem os conteúdos de cada nodo do grafo e, após, realizarem os testes adaptativos, para informar quais são seus conhecimentos sobre os conceitos estatísticos estudados, servindo como autoavaliação para o aluno e para o professor acompanhar o desempenho dos mesmos. O trabalho foi desenvolvido em grupos de dois ou três alunos. O SIENA considera que um nodo é predecessor do outro e só avança quando o aluno consegue obter um desempenho maior ou igual a 0,6 , em uma escala de 0,0 a 0,10 .

Para cada nodo do grafo foi desenvolvida uma sequência didática eletrônica com conceitos estatísticos integrados com os conteúdos referentes ao tema transversal Meio Ambiente seguindo as orientações dos PCN (BRASIL, 1998). Nesta investigação estes conteúdos foram utilizados como referencial para contextualizar as questões ambientais com o material de estudo contendo os conceitos estatísticos e as atividades que compõem a sequência didática eletrônica.

Sendo assim, a temática Meio Ambiente é abordada com o objetivo de incorporar as questões ambientais e a valorização da vida na prática educacional, buscando contribuir para a formação da cidadania, ou seja, visa não formar a competência e sim propor atividades que colaborem para o desenvolvimento da mesma. Portanto, as questões elaboradas para os testes adaptativos não visam avaliar o nível de compreensão dos alunos referente aos conteúdos do Meio Ambiente e, sim contribuir para o desenvolvimento de posturas pessoais e comportamentos sociais que lhes permitam viver numa relação construtiva consigo mesmo e com seu meio, colaborando para que a sociedade seja ambientalmente sustentável e justa.

Assim, primeiro foram realizados, pelos grupos, o estudo da sequência didática eletrônica do nodo Introdução à Estatística. Após terem estudado os conceitos estatísticos apresentados na sequência didática eletrônica, os alunos realizaram o teste e à medida em que estes foram sendo aprovados, o SIENA disponibiliza a sequência didática eletrônica do nodo seguinte. Caso o aluno não fosse aprovado no teste de cada nodo, o SIENA apresenta um link denominado recuperação de conteúdos, para o aluno retornar à sequência didática eletrônica e retomar os estudos e atividades sobre o conceito abordado, para então realizar um novo teste sobre este mesmo conceito, e assim sucessivamente. 


\title{
4.1. A Sequência Didática Eletrônica com os Conceitos Estatísticos e o tema transversal
} Meio Ambiente

Segundo Zabala (1998, p. 18), sequências didáticas são “[...] um conjunto de atividades ordenadas, estruturadas e articuladas para a realização de certos objetivos educacionais, que tem um princípio e um fim conhecido, tanto pelos professores como pelos alunos".

Dolz e Schneuwly (2004) consideraram que essas sequências didáticas são organizadas pelo professor com o objetivo de alcançar a aprendizagem de seus alunos, e envolvem atividades de aprendizagem e avaliação.

A sequência didática eletrônica desenvolvida está implementada no sistema SIENA, disponível no endereço eletrônico: http://siena.ulbra.br. Segundo Groenwald et al. (2009, p.2):

\begin{abstract}
A vantagem do uso de uma sequência didática em uma plataforma de ensino é a possibilidade da utilização de diferentes recursos, com padrão superior de qualidade, como vídeos-exemplo, textos com exemplos em movimento, ou seja, um conteúdo visual com maior qualidade de visualização. Assim, nesse ambiente virtual de aprendizagem, os alunos deixam de receber o mesmo conteúdo ao mesmo tempo e passam a percorrer caminhos diferenciados, de acordo com o seu perfil de estudante e com o seu desempenho.
\end{abstract}

Para a construção das sequências didáticas eletrônicas para cada conceito foram utilizados os seguintes recursos informáticos: editor de apresentação gráfica (o editor utilizado nas sequências didáticas foi o Power Point da Microsoft, salvo em ispring para a apresentação do material de estudo contendo os conceitos estatísticos a serem estudados; atividades lúdicas desenvolvidas no aplicativo JClic; jogos online; sites informativos referentes a questões ambientais.

Em cada nodo do grafo há uma porta de entrada, com os links de cada atividade, que permite aos alunos estudarem conforme suas preferências, ou seguirem a ordem indicada, conforme se apresenta na Figura 3, com os conceitos abordados no nodo Introdução à Estatística. 
Figura 3 - Porta de entrada do nodo Introdução à Estatística

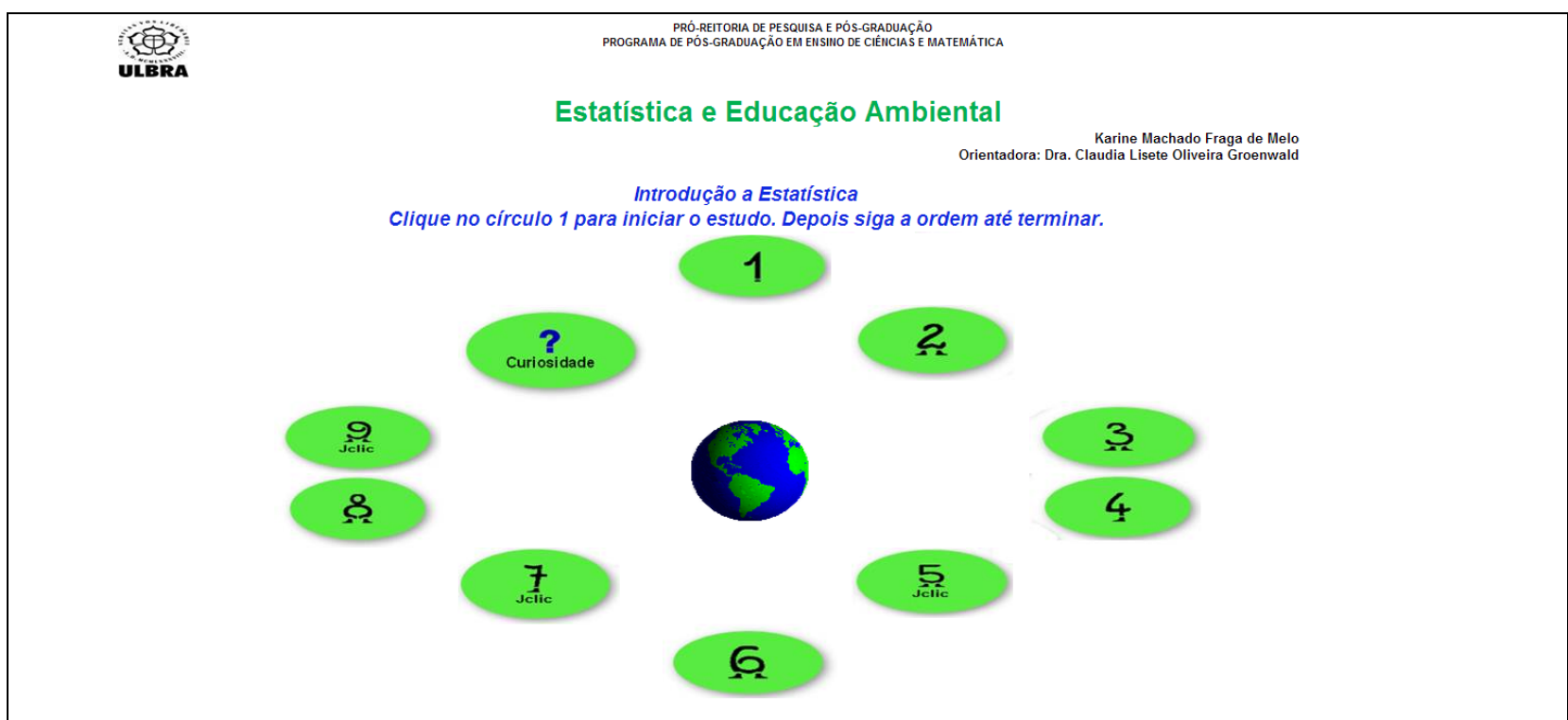

Fonte: http://siena.ulbra.br

O quadro da Figura 4, ilustra a distribuição dos links nas sequências didáticas eletrônicas construídas para cada nodo do grafo. Foram desenvolvidos 11 links, com o auxílio do software Power Point, em que apresentam explicações ilustradas dos conceitos estatísticos a serem estudados, 07 links com atividades lúdicas desenvolvidas no aplicativo JCLIC, 12 links contendo sites informativos sobre questões ambientais, 01 link com um teste online sobre sustentabilidade e 01 link com um jogo online abordando conceitos estatísticos.

Figura 4 - Quadro da distribuição dos links nas sequências didáticas eletrônicas

\begin{tabular}{|c|c|c|c|c|}
\hline Nodos & $\begin{array}{c}\text { Número de } \\
\text { apresentações } \\
\text { em } H T M L\end{array}$ & $\begin{array}{c}\text { Número de } \\
\text { atividades no } \\
\text { JCLIC }\end{array}$ & $\begin{array}{c}\text { Número de } \\
\text { Curiosidades } \\
\text { (Sites informativos } \\
\text { referentes a questões } \\
\text { ambientais) }\end{array}$ & $\begin{array}{c}\text { Jogos } \\
\text { online }\end{array}$ \\
\hline Introdução à Estatística & 06 & 03 & 01 & - \\
\hline Tabelas & 01 & 01 & $\begin{array}{c}04 \text { e } 01 \text { teste online } \\
\text { sobre sustentabilidade }\end{array}$ & - \\
\hline Gráficos & 01 & 01 & 03 & - \\
\hline Medidas de Tendência Central & 02 & 01 & - & - \\
\hline $\begin{array}{c}\text { Estatística e Educação Ambiental } \\
\text { Resolução de Problemas }\end{array}$ & 01 & 01 & - & - \\
\hline Conceitos Básicos de Estatística & - & - & & - \\
\hline
\end{tabular}

Fonte: a pesquisa

Buscou-se apresentar os conceitos estatísticos integrados aos conceitos ambientais, pois de acordo com Filippsen e Groenwald (2003),

[...] há a necessidade de uma proposta de Educação Matemática que se torne formadora de hábitos, atitudes e comportamentos que devem identificar, formular propostas e atuar no sentido de preservação do Meio Ambiente, bem como, 
desenvolver e aprofundar os conteúdos de Matemática, com compreensão e com uma visão crítica, formadora da cidadania.

De acordo com os PCN (BRASIL, 1998), o trabalho pedagógico com a questão ambiental centra-se no desenvolvimento de atitudes e posturas éticas, e no domínio de procedimentos, mais do que na aprendizagem estrita de conceitos.

A Figura 5 ilustra a introdução do conceito de média aritmética integrado aos conceitos conhecimento e valorização de alternativas para a utilização dos recursos naturais e análise crítica de atividades de produção e práticas de consumo. Nesta sequência didática buscou-se oferecer meios efetivos para cada aluno observar e analisar fatos e situações do ponto de vista ambiental, de forma crítica, reconhecendo a necessidade e as oportunidades de atuar de modo propositivo, para garantir um Meio Ambiente saudável e a boa qualidade de vida (BRASIL, 1998).

Figura 5 - Material de Estudo com a introdução do conceito de média aritmética

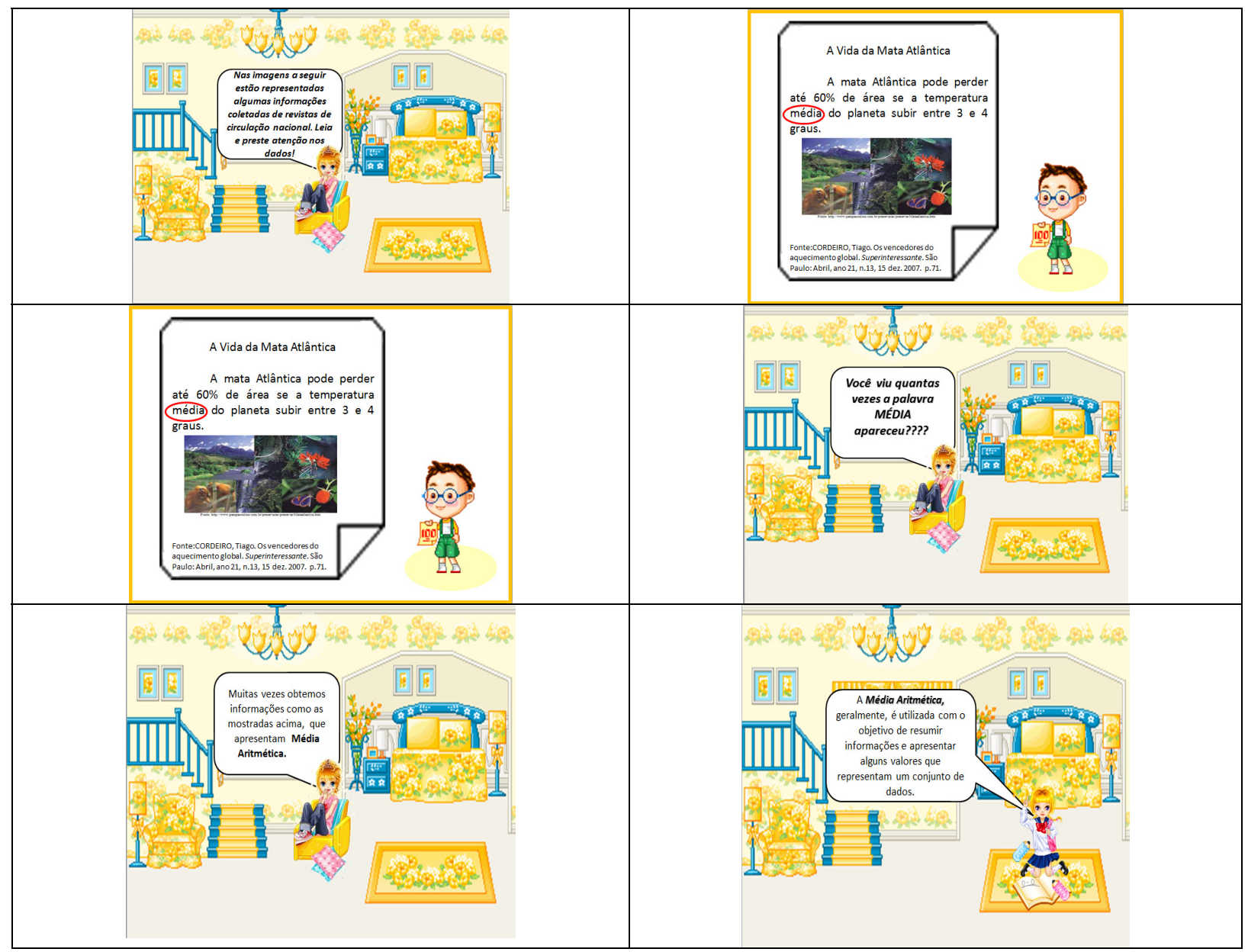

Fonte: http://siena.ulbra.br 
Com relação aos conceitos estatísticos abordados, buscou-se apresentá-los aos alunos de maneira contextualizada. A Estatística em sala de aula "[...] deve estar em consonância com as necessidades, os interesses e as experiências de vida dos alunos" (ROSETTI, 2007 apud ALVES; SANTOS, 2011, p. 3). O objetivo principal centra-se em os alunos coletarem, organizarem e interpretarem a informação. Baseados na análise da informação, os mesmos devem formular conjecturas, tirar conclusões e fundamentá-las.

Na sequência, também foram desenvolvidos, com o software JClic, projetos de atividades. Para os projetos foram elaboradas atividades de preencher lacunas, resposta escrita pelos estudantes, completar texto, associação simples e complexa, identificar células, cata palavras, jogo da memória e palavra cruzada. Segundo o National Council of Supervisors of Mathematics [NCTM] (1991),

os alunos deverão ser envolvidos em atividades de aprendizagem ricas e diversificadas, nomeadamente a realização de trabalhos de grupo e de projetos, atividades interdisciplinares com o uso de calculadora e computadores, no sentido de enfrentarem os problemas, do mundo que nos rodeia, com confiança.

O quadro a seguir, Figura 6, apresenta os projetos de atividades desenvolvidos com o software JClic, para cada nodo do grafo.

Figura 6 - Quadro da distribuição dos projetos de atividades desenvolvidos com o software JClic

\begin{tabular}{|c|c|c|c|}
\hline Nodos & Projetos desenvolvidos & $\begin{array}{l}\text { Tipos de atividades } \\
\text { elaboradas }\end{array}$ & Número de atividades \\
\hline \multirow[t]{8}{*}{ Introdução à Estatística } & \multirow[t]{2}{*}{ Projeto 01} & Preencher lacunas & 02 \\
\hline & & Completar texto & 01 \\
\hline & Projeto 02 & Preencher lacunas & 02 \\
\hline & \multirow[t]{5}{*}{ Projeto 03} & $\begin{array}{l}\text { Painéis de identificar } \\
\text { células }\end{array}$ & 02 \\
\hline & & Associação simples & 01 \\
\hline & & Preencher lacunas & 01 \\
\hline & & Associação complexa & 01 \\
\hline & & Palavras cruzadas & 01 \\
\hline \multirow[t]{3}{*}{ Tabelas } & \multirow[t]{3}{*}{ Projeto 01} & Preencher lacunas & 02 \\
\hline & & Completar texto & 01 \\
\hline & & Associação complexa & 01 \\
\hline \multirow[t]{3}{*}{ Gráficos } & \multirow[t]{3}{*}{ Projeto 01} & Associação simples & 01 \\
\hline & & Preencher lacunas & 07 \\
\hline & & Jogo da memória & 01 \\
\hline \multirow{3}{*}{$\begin{array}{l}\text { Medidas de Tendência } \\
\text { Central }\end{array}$} & \multirow[t]{3}{*}{ Projeto 01} & Preencher lacunas & 07 \\
\hline & & Caça palavras & 01 \\
\hline & & Painéis de Informação & 03 \\
\hline \multirow{3}{*}{$\begin{array}{l}\text { Estatística e Educação } \\
\text { Ambiental Resolução de } \\
\text { Problemas }\end{array}$} & \multirow[t]{3}{*}{ Projeto 01} & Preencher lacunas & 06 \\
\hline & & Resposta escrita & 02 \\
\hline & & Associação complexa & 02 \\
\hline
\end{tabular}

Fonte: a Pesquisa 
A Figura 7 ilustra uma atividade de organização de dados em tabelas, desenvolvida com o auxilio do Jclic, em que os alunos a partir do texto apresentado devem coletar os dados fornecidos e organizá-los. Para montar o painel com o texto foi utilizado o recurso do Jclic de completar texto e, para possibilitar a construção da tabela, foi utilizada a associação complexa ${ }^{5}$. A atividade é concluída no momento em que os alunos relacionarem corretamente todas as informações do segundo painel com o primeiro. A situação-problema apresentada nesta atividade tem como objetivo levar os alunos a recolher dados e informações e elaborar formas para organizá-los e expressá-los sob forma de tabela.

Figura 7 - Atividade de construção de tabela

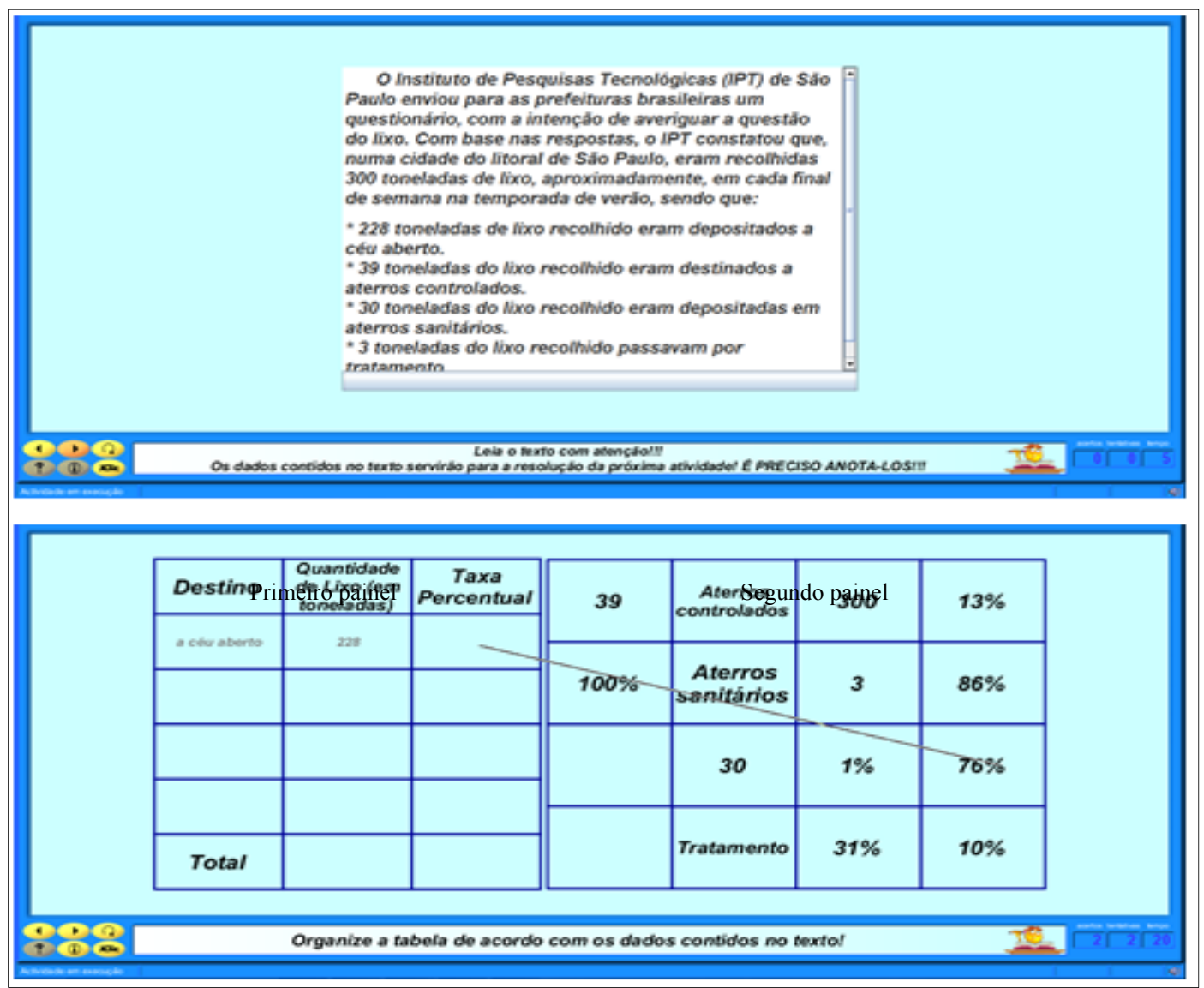

Fonte: http://siena.ulbra.br

\footnotetext{
${ }^{5}$ A associação complexa é uma atividade onde são visualizados dois conjuntos de informações, que podem apresentar um número menor de elementos, possibilitando diversos tipos de relação: um a um, diversos a um, elementos sem assinalar, entre outros. Ao criar uma atividade desse tipo, por padrão, visualizamos as setas guardando uma relação de um quadro para outro. Nesta atividade esse recurso foi adaptado e utilizado para desenvolver uma atividade em que os alunos deverão construir uma tabela com base nas informações fornecidas pelo texto.
} 
$\mathrm{Na}$ sequência didática também foram apresentados sites informativos referentes a questões ambientais. Para acessar estes sites era necessário acessar a porta de entrada de cada nodo do grafo e clicar nos links Curiosidades. O quadro a seguir, Figura 8, apresenta a distribuições dos sites informativos selecionados para cada nodo do grafo.

Figura 8- Quadro da distribuição dos sites informativos para cada nodo do grafo

\begin{tabular}{|c|c|c|}
\hline Nodo & Endereço eletrónico do site informativo & Tema ambiental abordado \\
\hline $\begin{array}{l}\text { Introdução à } \\
\text { Estatística }\end{array}$ & $\begin{array}{l}\text { http://www.smartkids.combr/especiais/animais-em- } \\
\text { extincao.html }\end{array}$ & Animais em extinção \\
\hline \multirow[t]{5}{*}{ Tabelas } & $\begin{array}{l}\text { http: } / / \text { www.recicloteca.org.br/Default.asp } ? \text { Editoria }=4 \& \text { Su } \\
\text { bEditoria }=12\end{array}$ & Dicas de coleta seletiva \\
\hline & $\begin{array}{l}\text { http://planetasustentavel.abril.com.br/noticia/lixa/conteudo } \\
250715 . \mathrm{shtml}\end{array}$ & Manual de reciclagem \\
\hline & http://www.compam.com.br/porquereciclar.htm & Por que reciclar? \\
\hline & http://www.compam.com.br/coletaseletiva.htm & Coleta Seletiva \\
\hline & $\begin{array}{l}\text { http://super.abril.com.br/testes/teste-verde- } \\
\text { sustentabilidade-faz-parte-sua-vida- } 574649 . \text { shtml }\end{array}$ & Teste de sustentabilidade \\
\hline \multirow[t]{3}{*}{ Gráficos } & http://www.sobiologia.com br/conteudos/Agua/ & Agua \\
\hline & $\begin{array}{l}\text { http://www.youtube.com } / \text { watch? } v=t J o D Z v 32 \text { e3o\&feature }= \\
\text { player_embedded\#! }\end{array}$ & $\begin{array}{l}\text { Plano Nacional de Recursos } \\
\text { Hidricos }\end{array}$ \\
\hline & $\begin{array}{l}\text { http://www.sppert.combr/Brasil/Meio_Ambiente/Conserva } \\
\% \text { C } 3 \% \text { A7\% } \% \% A 30 \text { Ambiental/ }\end{array}$ & $\begin{array}{lll}\text { Conservação Ambiental no } \\
\text { Brasil }\end{array}$ \\
\hline \multirow{3}{*}{$\begin{array}{l}\text { Medidas de } \\
\text { Tendência } \\
\text { Central }\end{array}$} & $\begin{array}{l}\text { http://www.ceee.com br/pportal/ceee/Component/Controlle } \\
\text { r.aspx?CC }=1895\end{array}$ & $\begin{array}{l}\text { Responsabilidade } \\
\text { Socioambiental }\end{array}$ \\
\hline & $\begin{array}{l}\text { http://www.coletivoverdecom.br/lampadas- } \\
\text { sustentabilidade/ }\end{array}$ & Qual a lâmpada certa? \\
\hline & http://www.natureba.combr/economia-agua.htm & $\begin{array}{l}\text { Dicas para evitar o desperdício } \\
\text { de água e exigir a preservação } \\
\text { dos recursos hídricos }\end{array}$ \\
\hline
\end{tabular}

Fonte: a Pesquisa

A seleção dos sites foi feita de acordo com o conteúdo ambiental abordado em cada nodo do grafo, tendo como objetivo ressaltar a complexidade dos problemas ambientais e, em consequência, a necessidade de desenvolver o sentido crítico e as atitudes necessárias para resolvê-los. A Figura 9 apresenta um dos sites informativos selecionados para o nodo Tabelas. Neste site são abordadas dicas de coleta seletiva. 
Figura 9 - Site informativo apresentado no nodo Tabelas

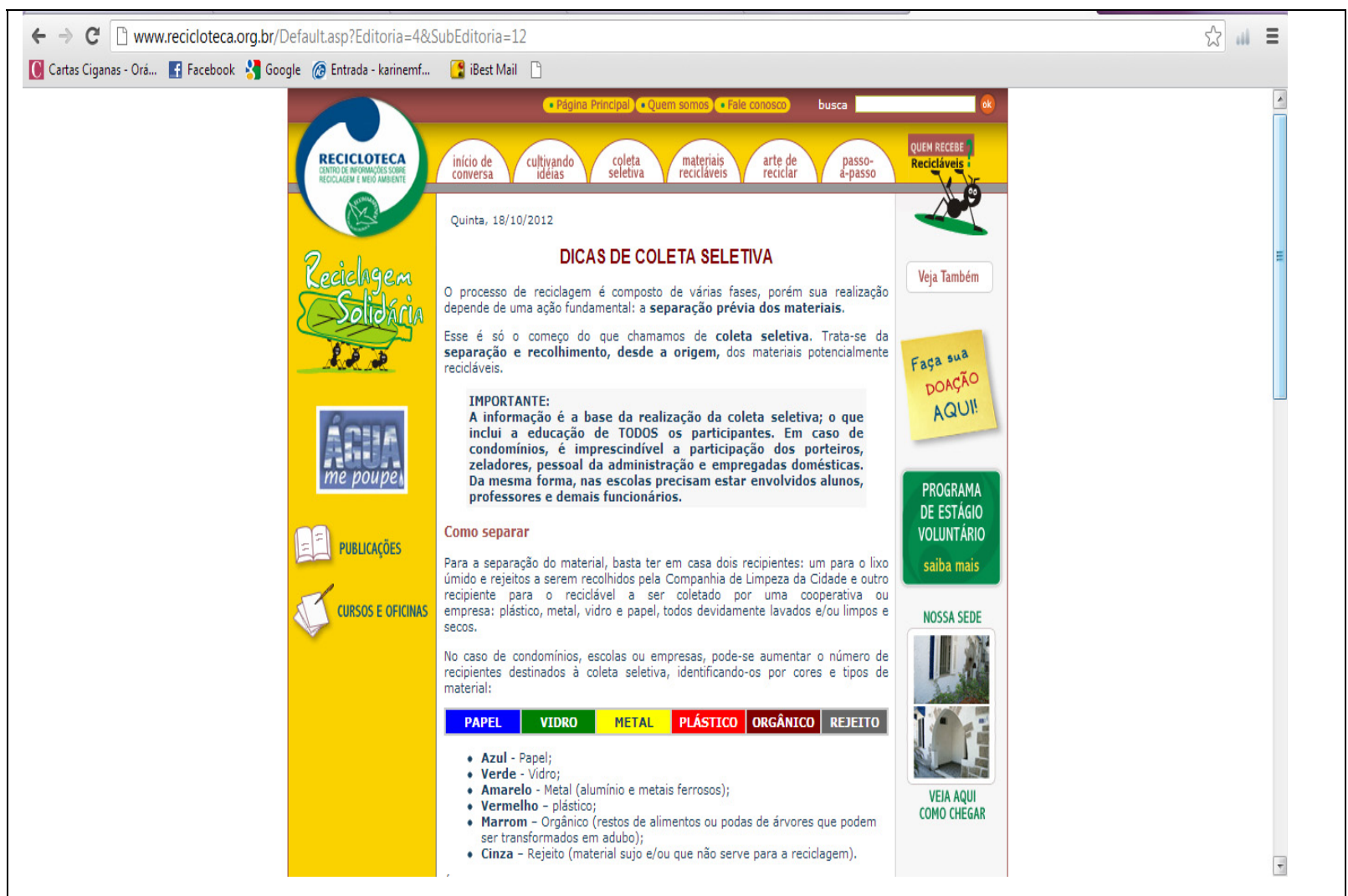

Fonte: http://www.recicloteca.org.br/Default.asp? Editoria $=4 \&$ SubEditoria $=12$

A sequência didática eletrônica desenvolvida para o nodo Estatística e Educação Ambiental Resolução de Problemas não apresenta sites informativos. Para este nodo foi selecionado o jogo online Glória da Estatística, disponível no endereço eletrônico: $<$ http://www.alea.pt/ttml/trivial/html/jgloria/Gloria3ciclo/gloria.htm >.

O jogo Glória da Estatística, ilustrado na Figura 10, consiste num tabuleiro com um conjunto de casas que cada jogador (até um máximo de 4) deve percorrer até alcançar a última casa. No decorrer do jogo, o jogador deverá responder a diversas questões sobre Estatística, para progredir. O objetivo do jogo é chegar ao final do tabuleiro em $1^{\circ}$ lugar. 
Figura 10 - Jogo online A Glória da Estatística

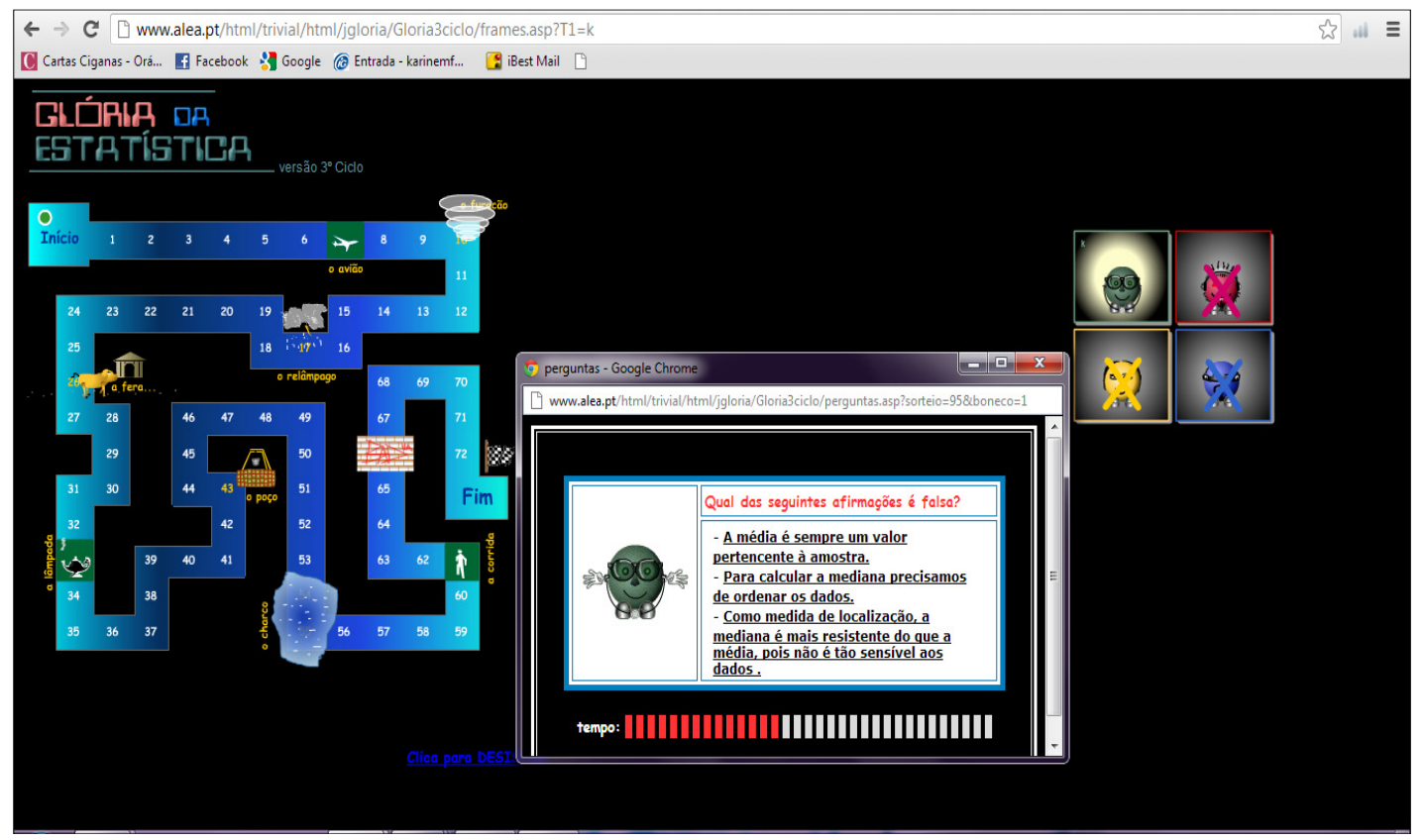

Fonte: http://www.alea.pt/html/trivial/html/jgloria/jgloria.htm\#

Este jogo foi desenvolvido no âmbito do projeto Ação Local Estatística Aplicada (ALEA). O ALEA constitui-se no âmbito da Educação, da Sociedade da Informação, da Informação Estatística, da Formação para a Cidadania e da Literacia Estatística como um contributo para a elaboração e disponibilização de instrumentos de apoio ao ensino da Estatística para os alunos e professores do Ensino Básico e Secundário, tendo como principal suporte um sítio na web.

\section{Análise dos bancos de dados do SIENA e dos registros dos grupos no desenvolvimento dos testes adaptativos}

O desempenho dos grupos foi analisado através dos dois bancos de dados, gerados pelo SIENA, para cada teste realizado pelos alunos em cada conceito do grafo. As notas estão compreendidas no intervalo [0,1 e 1], sendo que foi estabelecido o índice 0,6 para o desempenho considerado satisfatório para cada conceito do grafo.

A Tabela 1 apresenta os resultados que os grupos obtiveram nos testes adaptativos para cada conceito. 
Tabela 1 - Avaliação dos grupos nos Testes Adaptativos Informatizados

\begin{tabular}{|c|c|c|c|c|c|c|c|c|c|c|}
\hline \multirow{2}{*}{$\begin{array}{l}\text { Conceitos } \\
\text { Grupos }\end{array}$} & \multicolumn{2}{|c|}{$\begin{array}{l}\text { Introdução à } \\
\text { Estatística }\end{array}$} & \multicolumn{2}{|c|}{ Tabelas } & \multicolumn{2}{|c|}{ Gráficos } & \multicolumn{2}{|c|}{$\begin{array}{l}\text { Medidas de } \\
\text { Tendência } \\
\text { Central }\end{array}$} & \multicolumn{2}{|c|}{$\begin{array}{l}\text { Estatística e } \\
\text { Educação } \\
\text { Ambiental } \\
\text { Resolução de } \\
\text { Problemas } \\
\end{array}$} \\
\hline & Teste 1 & Teste 2 & Teste 1 & Teste 2 & Teste 1 & Teste 2 & Teste 1 & Teste 2 & Teste 1 & Teste 2 \\
\hline Grupo 1 & 0,385 & 0,997 & 0,593 & 0,610 & 0,954 & $\cdots$ & 0,100 & 0,901 & 0,143 & 0,610 \\
\hline Grupo 2 & 0,100 & 0,754 & 0,966 & $\ldots$ & 0,994 & $\ldots$ & 0,983 & 1,000 & 0,962 & $\cdots$ \\
\hline Grupo 3 & 0,100 & 0,997 & 1,000 & $\ldots$ & 0,999 & $\ldots$ & 0,999 & $\ldots$ & 1,000 & $\ldots$ \\
\hline Grupo 4 & 0,766 & - - & 0,273 & 0,999 & 0,999 & $\cdots$ & 0,385 & 0,991 & 0,143 & 0,773 \\
\hline Grupo 5 & 0,200 & 0,997 & 0,100 & 1,000 & 0,999 & - - & 0,984 & -- & 0,100 & 0,923 \\
\hline Grupo 6 & 0,484 & 0,991 & 1,000 & $\cdots$ & 0,999 & $\cdots$ & 0,964 & $\cdots$ & 0,280 & 0,964 \\
\hline Grupo 7 & 0,100 & 0,996 & 0,100 & 1,000 & 0,999 & $\cdots$ & 0,493 & 0,998 & 0,996 & $\cdots$ \\
\hline Grupo 8 & 0,974 & - - & 0,100 & 1,000 & 1,000 & $\cdots$ & 1,000 & $\cdots$ & 1,000 & $\cdots$ \\
\hline Grupo 9 & 0,200 & 0,976 & 0,999 & 0,994 & 0,999 & 0,936 & 0,999 & $\cdots$ & 0,978 & $\cdots$ \\
\hline Grupo 11 & 0,983 & $\ldots$ & 0,593 & 1,000 & 0.999 & - - & 1,000 & - - & 0,980 & $\cdots$ \\
\hline Grupo 12 & 0,988 & 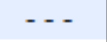 & 1,000 & - - & 1,000 & $\cdots$ & 0,997 & - - & 1,000 & $\cdots$ \\
\hline Grupo 13 & 0,467 & 0,701 & 1,000 & $\cdots$ & 0,999 & $\cdots$ & 0,998 & $\cdots$ & 0,998 & $\cdots$ \\
\hline Média & 0,479 & & 0,644 & & 0,995 & & 0,824 & & 0,715 & \\
\hline
\end{tabular}

Fonte: banco de dados SIENA [http://siena.ulbra.br]

De acordo com as médias do teste 1, observou-se que, neste primeiro teste, no conceito Introdução à Estatística, um maior número de grupos apresentou dificuldades, pois oito dos doze grupos que realizaram o teste obtiveram desempenho inferior a 0,6 .

Os alunos não apresentaram dificuldades na leitura e interpretação de gráficos, observou-se que nenhum dos grupos necessitou fazer a recuperação de estudos para este conceito, a média no teste foi de 0,995. Os grupos, nos conceitos Tabelas, Medidas de Tendência Central e Estatística e Educação Ambiental Resolução de Problemas apresentaram um rendimento satisfatório. No nodo Tabelas, observou-se que o grupo 9 realizou o primeiro teste e atingiu média superior a 0,6 sendo aprovado para o próximo nodo, no entanto, o grupo fez um segundo teste no qual também atingiu a média, isto ocorreu porque a plataforma SIENA não limita a quantidade de testes a serem realizados, ou seja, os grupos podem fazer quantos testes quiserem para um mesmo nodo. Os alunos também podem utilizar esta possibilidade para estudo do conteúdo que está sendo trabalhado.

Além disso, observou-se que para os conceitos em que os grupos obtiveram desempenho inferior a 0,6, o SIENA direcionou-os para realizar estudos de revisão e atividades didáticas propostas na sequência didática eletrônica, a fim de possibilitar uma recuperação do conteúdo proposto no nodo não aprovado, para então realizar um segundo teste. 
Para os alunos que realizaram o segundo teste, nos nodos em que não haviam alcançado o índice 0,6, após os estudos de recuperação, os dados fornecidos pelo banco de dados do SIENA, conforme a Tabela 1, apontam uma melhora significativa no desempenho destes.

Nesse sentido, o uso de recursos informáticos, de acordo com Groenwald e Ruiz (2006), pode influenciar beneficamente quando utilizados como suporte ao trabalho docente, contribuindo para a agilização das tarefas dos mesmos, como fonte de informação do conhecimento real dos alunos, ou na utilização de sistemas inteligentes, que auxiliem o professor na sua docência. Com a calculadora e o computador na sala de aula, o professor possui mais condições de transformar-se em mediador do processo educativo.

\section{Considerações finais}

Nesta investigação foi possível constatar que a aplicação da sequência didática eletrônica contextualizada com questões ambientais, contribuiu para o processo de ensino e aprendizagem de conceitos estatísticos desenvolvidos nos anos finais do Ensino Fundamental, visto que esta foi utilizada como recurso didático para estudo dos conceitos que já haviam sido trabalhados em sala de aula, o que possibilitou aos alunos: revisar, aprofundar e acrescentar novos conceitos aos já estudados, sob uma nova forma de abordá-los, contemplando: a contextualização de questões de urgência social; o trabalho em grupo como meio de favorecer a troca de conhecimento e discussões entre os alunos, contribuir para o desenvolvimento de atitudes de cooperação e o uso das Tecnologias da Informação e Comunicação como recurso didático no processo de ensino e aprendizagem dos conceitos estatísticos.

Em relação aos nodos, constatou-se que, através do desempenho dos alunos fornecido pelo banco de dados do SIENA, um número maior de grupos apresentou dificuldades no nodo Introdução à Estatística. Os grupos não apresentaram dificuldades na leitura e interpretação de gráficos, observou-se que nenhum dos grupos necessitou fazer a recuperação de estudos para este conceito. Identifica-se para este nodo, a presença dos três níveis de compreensão que podem ser aplicados em gráficos estatísticos, descritos por Curcio (1989). Nos conceitos Tabelas, Medidas de Tendência Central e Estatística e Educação Ambiental Resolução de Problemas, os grupos apresentaram um rendimento satisfatório. 
Percebe-se ainda, que dos doze grupos que realizaram a experiência, dez atingiram os objetivos estabelecidos para os conceitos estatísticos e dois atingiram parcialmente, constatase que para estes dois grupos as dificuldades apresentadas, no primeiro teste, foram reduzidas à medida em que os mesmos não aprovados realizavam os estudos de recuperação e as atividades didáticas propostas na sequência didática respectiva a cada nodo do grafo, no intervalo destes testes, porém não foram sanadas completamente.

\section{Referências}

ALMEIDA, Maria do Rosário. Imagens sobre o ensino e a aprendizagem da Estatística. Lisboa: Instituto de Inovação Educacional, 2002.

ALVES, Marcos Wederson; SANTOS, Rosiane de Jesus. Uma Abordagem do Ensino de Estatística no Ensino Fundamenltal. In: XII Conferência Interamericana de Educação Matemática, 2011, Recife. Anais. Recife, 2011.

BATANERO, Carmen. Difficultades de los Estudiantes en los Conceptos Estadísticos Elementales: El Caso de Las Medidas de Posición Central. In: LOUREIRO, C.; OLIVEIRA, F.; BRUNHEIRA, L. (Eds.), Ensino e Aprendizagem da Estatística. Lisboa: Sociedade Portuguesa de Estatística, Associação de Professores de Matemática, Departamento de Educação e de Estatística e Investigação Operacional da Faculdade de Ciências da Universidade de Lisboa, 2000.

Secretaria de Educação Fundamental. Parâmetros Curriculares Nacionais: Matemática: introdução aos Parâmetros Curriculares Nacionais. Brasília: MEC/SEF, 1998 .

- Secretaria de Educação Fundamental. Parâmetros Curriculares Nacionais: terceiro e quarto ciclos: apresentação dos temas transversais. Brasília: MEC/SEF, 1998.

BROCARDO, Joana; MENDES, Maria de Fátima Pista Calado. Processos usados na resolução de tarefas estatísticas. Quadrante, 10(1), pp. 33-58, 2001.

CAMPOS, Celso Ribeiro; et al. Educação Estatística no Contexto da Educação Crítica. Bolema. Rio Claro (SP), v. 24, n. 39, ago. 2011.

CARVALHO, Carolina. Interacção entre pares. Contributos para a promoção do desenvolvimento lógico e do desempenho estatístico no $7^{\circ}$ ano de escolaridade. Tese de doutoramento não publicada, Universidade de Lisboa, Lisboa, 2001.

CARVALHO, Carolina; CÉSAR, M. Interagir para aprender: Um caso de trabalho colaborativo em estatística. In: SILVA, B.; ALMEIDA, L. (Orgs.). Actas do VI Congresso Galaico Português de Psicopedagogia (vol.2). Braga: Centro de Estudos em Educação e Psicologia da Universidade do Minho, 2001. 
CARVALHO, Carolina. Um olhar da psicologia pelas dificuldades dos alunos em conceitos estatísticos. In: FERNANDES, J. A. SOUSA, M. V; RIBEIRO, S. A. (Orgs.). Ensino e Aprendizagem de Probabilidades e Estatística. Actas do $1^{\circ}$ Encontro de Probabilidades e Estatística na Escola. Braga: Centro de Investigação em Educação da Universidade do Minho, 2004.

CARVALHO, Carolina Fernandes de, FERNANDES, José Antônio; RIBEIRO, Sonia Alexandra Lopes. Caracterização e implementação de tarefas de Estatística: um exemplo no 7.o ano de escolaridade. ZETETIKE- Cempem - FE - Unicamp - v. 15 - n. 28 - jul./dez. - 2007. Disponível em: < http://repositorium.sdum.uminho.pt/handle/1822/8454> Acesso em: 17 jul 2012.

CURCIO, F.R. Developing graph comprehensions. Virginia: National Council of Teachers of Mathematics. ISBN 0-87353-277-5. Pp5-6, 1989.

D’AMBRÓSIO, Ubiratan. Desafios da educação matemática no novo milênio. Educação Matemática em Revista, São Paulo: SBEM, n. 11, p . 14 - 17, dez. 2001.

DOLZ, Joaquim; NOVERRAZ, Michele; SCHNEUWLY, Bernard. Seqüências didáticas para o oral e a escrita: apresentação de um procedimento. In: SCHNEUWLY, Bernard; DOLZ, Joaquim. Gêneros orais e escritos na escola. Tradução de Roxane Rojo e Glaís Sales Cordeiro. Campinas, SP: Mercado das Letras, 2004, p. 95-128.

FILIPPSEN, Rosana Maria Jardim; GROENWALD, Claudia Lisete Oliveira. Educação matemática e educação ambiental: educando para o desenvolvimento sustentável. Canoas, 2003. Disponível em: <http://www.liberato.com.br/upload/arquivos/0131010716351516.pdf > Acesso em 07 de set. de 2010

GIGANTE, Ana Maria Beltrão; SILVA, Maria Rejane Ferreira da; SANTOS, Monica Bertoni dos. Referências curriculares do Estado do Rio Grande do Sul: matemática e suas tecnologias/Secretaria de Estado da Educação. Porto Alegre:SE/DP, 2009.

GROENWALD, Claudia Lisete Oliveira; SILVA, Carmen Kaiber da; MORA, Castor David. Perspectivas em Educação Matemática. Acta Scientiae. Canoas. v. 6, n. 1, p. 37-55. Jan./jun. 2004.

GROENWALD, Claudia Lisete Oliveira; RUIZ, Lorenzo Moreno. Formação de Professores de Matemática: uma proposta de ensino com novas tecnologias. Acta Scientiae, Canoas, v.8, n.2, jul./dez.2006.

GROENWALD, Claudia Lisete Oliveira et al. Sequência Didática com Análise Combinatória no Padrão SCORM. Bolema, Rio Claro, ano22, n.34, p.27-56, 2009.

LOPES, Celi E. O ensino da estatística e da probabilidade na educação básica e a formação dos professores. 2008. Cad. Cedes, Campinas, SP, v. 28, n. 74, p. 57-73, jan./abr. 2008. Disponível em $<$ http://www.cedes.unicamp.br $>$ 
MUNHOZ, Regina Helena; DINIZ, Renato Eugênio da Silva. Educação ambiental e ensino de matemática: abordagem do tema "depredação do patrimônio escolar" em uma escola estadual. São Paulo, 2006. Disponível em:

$<$ http:// www.fae.ufmg.br/abrapec/viempec/CR2/p446.pdf $>$ Acesso em 05 de jul. de 2010

NCTM, National Council of Teachers of Mathematics (1991). Normas para o currículo e a avaliação em matemática escolar. Lisboa: Associação de Professores de Matemática e Instituto de Inovação Educacional.

PEREZ, Jeferson de Freitas; PAULO, Rosa Monteiro de. Educação Ambiental: em busca de caminhos e perspectivas. 2008. Disponível em:

http://www2,rc.unesp.br/eventos/matematica/ebrapem2008/upload/195-1-a-gt9 perez ta.pdf.

Acesso em 5 de jul. de 2010

POSSAS, Ana Raquel Oliveira da Costa. A prática pedagógica enquanto mediação entre a etnomatemática e a educação ambiental. 2003. 152 p. Dissertação (Mestrado em Desenvolvimento Sustentável), Centro de desenvolvimento sustentável, Universidade de Brasília, Macapá, 2003. Disponível em: $<\quad$ http:// www.unbcds.pro.br/publicaçoes/AnaRaquel.pdf $>$ Acesso em: 06 de jul. de 2010.

RIBEIRO, Sonia Alexandra Lopes. O Ensino de Estatística no $7^{\mathbf{0}}$ ano de Escolaridade. Dissertação de Mestrado. Universidade do Minho, 2005. Disponível em: < http://repositorium.sdum.uminho.pt/.../TESE\%20DE\%20ESTAT\%C3\%8DSTICA_fi... .Acesso em: 07 set de 2012.

ZABALA, Antoni. A prática educativo: como ensinar. Porto Alegre: ArtMed, 1998. 